\title{
Surgical Approach to Extensive Hidradenitis Suppurativa in the Perineal/Peri-Anal and Gluteal Regions
}

\author{
Adam Klipfel
}

Published online: 10 January 2009

(c) Société Internationale de Chirurgie 2009

I thank the authors for an excellent review and series of patients on the topic of perineal/buttocks hidradenitis and its management. The authors discussed the management of severe stage III hidradenitis, which consists of diffuse involvement with multiple interconnected tracts and abscesses [1]. The article describes using a full excision technique to treat this condition, which, as can be seen in the figures, involves removing all the skin overlying this area. The technique can be quite a morbid operation with a long recovery. It certainly is true that it is necessary in some cases and is an adequate method for treating the condition; however, consideration should be given to using a less morbid option initially and saving the full excision for cases that cannot be done in any another way.

The first consideration in any patient with severe hidradenitis is to control sepsis. This can be done by draining the abscesses and placing setons in addition to administering antibiotics. The setons, which allow continued drainage of the infection, are run from one abscess to another and do not go into the anal canal. It may take an extended period of time to allow the infection to subside and for the tracts to become smaller around the setons. The patient may be kept on antibiotics during this period, which allows further control of the sepsis as well. An attempt to remove the setons can be undertaken, but the chance of recurrence is high. By removing some of the setons, though, it may be possible for a few of the tracts to close, thereby reducing the number of tracts to treat with aggressive surgery.

\footnotetext{
A. Klipfel $(\bowtie)$

Rhode Island Colorectal Clinic, 334 East Avenue, Pawtucket, RI 02860, USA

e-mail: aaklipfel@yahoo.com
}

The other important issue is to make sure that there is no connection to the anal or rectal area and that the problem is purely hidradenitis and not related to anorectal disease. Surgical treatment is easier once the sepsis is under control and these fistulous tracts have become chronic and smaller. As they do become chronic, they develop a fibrous base; and they can then be unroofed and either marsupialized or left open to heal secondarily. Even if a wide excision is deemed necessary, the setons and time required for healing can reduce the area of subsequent excision. Using this less morbid surgical technique, however, may increase the recurrence rate.

Hidradenitis suppurativa of the perianal and gluteal area is an unusual but difficult disease, and treatment must be individualized to each patient depending on the location and the extent of disease. It is important for surgeons treating this disease to know all the options and utilize them in the appropriate situation to allow the best possible outcomes for patients with the least morbidity. See Bocchini et al. [2] and Bordier-Lamy et al. [3] for further discussion of this interesting disorder.

\section{References}

1. Balik E, Eren T, Bulut T et al (2009) Surgical approach to extensive hidradenitis suppurativa in the perineal/peri-anal and gluteal regions. World J Surg. doi:10.1007/s00268-008-9845-9 [epub ahead of print]

2. Bocchini SF, Habr-Gama A, Kiss DR et al (2003) Gluteal and perianal hidradenitis suppurativa: surgical treatment by wide excision. Dis Colon Rectum 46:944-949

3. Bordier-Lamy F, Palot JP, Vitry F et al (2008) Surgical treatment of hidradenitis suppurativa: a retrospective study of 93 cases. Ann Dermatol Venereol 135:373-379 